\title{
On Two Well-Known Neobisiid Pseudoscorpions (Pseudoscorpiones: Neobisiidae) from Iran
}

\author{
Mahrad Nassirkhani \\ Entomology Department, Faculty of Agriculture and Natural Resources, \\ Islamic Azad University, Arak branch, Arak \\ greenartificialturfgrass@gmail.com
}

\begin{abstract}
Recently, a few specimens belonging to two well-known pseudoscorpion species Roncus corimanus Beier and Acanthocreagris ronciformis (Redikorzev) have been collected from Iran. In this study, both are redescribed and illustrated. Also, a few notes on A. aucta (Redikorzev) and A. abaris Curčić which are the synonyms of A. ronciformis are given.
\end{abstract}

Keywords: Arachnida, Neobisiidae, taxonomy, habitat, Iran, the Middle East.

\section{INTRODUCTION}

The family Neobisiidae Chamberlin is poorly studied in Iran, e.g. total of only 10 different species belonging to three valid genera have been since reported from Iran: Neobisium (Neobisium) alticola Beier, 1973 from Azerbaijan and Mazandaran Provinces- Northern Iran, $N$. (N.) erythrodactylum (L. Koch, 1873) from Tehran and Mazandaran Provinces- Northern Iran, N. (N.) fuscimanum (C.L. Koch, 1843) from Mazandaran Province-Northern Iran, N. (N.) validum (L. Koch, 1873) from Fars Province-Southern Iran and also from Mazandaran Province-Northern Iran, Acanthocreagris caspica (Beier, 1971) from Mazandaran Province-Northern Iran, A. iranica Beier, 1976 and A. ronciformis (Redikorzev, 1949) from Mazandaran Province-Northern Iran, Roncus corimanus Beier, 1951 from Mazandaran and Guilan Provinces-Northern Iran, R. microphthalmus (Daday, 1889) from Azerbaijan Province-Northern Iran, and $R$. viti Mahnert, 1974 from Guilan Province-Northern Iran [1, 2, 3, 4, 5].

Recent pseudoscorpion collecting in Iran recovered a male specimen of A. ronciformis which is the first record of the family from Khorasan Province-Eastern Iran, as well as a female of $R$. corimanus collected from Mazandaran Province-Northern Iran which shows that the species is dominantly distributed in northern parts of Iran. In due attention to the loss of well description of $R$. corimanus with modern terminology, the newly collected specimen is fully redescribed, and also a few interesting notes with a short description of A. ronciformis are given in this contribution.

\section{Materials AND MethodS}

The specimens used in this study were directly collected by hand, preserved in ethanol $70 \%$, cleared by lactic acid $60 \%$, and permanently mounted on dished glass microscope slides in Swan's fluid. The specimens which are deposited in the Acarology Laboratory, Islamic Azad University of Arak (IAUA) examined by using an Olympus BH-2 compound microscope, measured with an ocular graticule, and illustrated with the aid of a drawing tube attachment. Morphological terminology and mensuration follow Chamberlin [6], Harvey [7], Harvey et al. [8] and Judson [9].

The following trichobothrial abbreviations employed: $e b=$ external basal; $e s b=$ external sub-basal; $e s t=$ external sub-terminal; et $=$ external terminal; $i b=$ internal basal; is $b=$ internal sub-basal; ist $=$ internal sub-terminal; $i t=$ internal terminal; $t=$ terminal; $s t=$ sub-terminal; $b=$ basal; $s b=$ sub-basal. In addition, the following abbreviations are used: $\mathrm{mm}=$ millimeter; $\mathrm{L}=$ length; $\mathrm{W}=$ width and $\mathrm{D}=$ depth. 
Acanthocreagris ronciformis (Redikorzev, 1949)
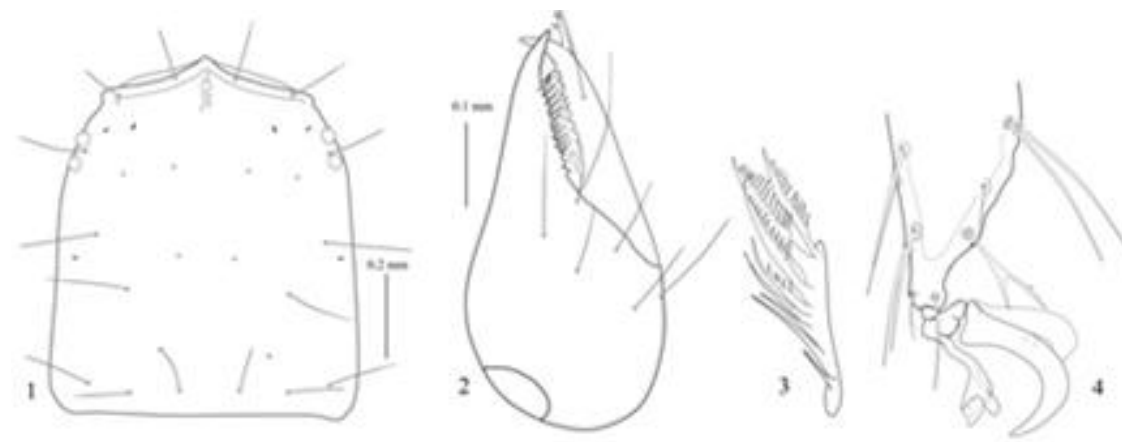

Figures1-4. Acanthocreagris Ronciformis (Redikorzev, 1949), §.: 1. Carapace, Dorsal View; 2. Chelicera (Serrula Exterior Omitted); 3. Rallum; 4. Tarsus IV (Showing Sub-Terminal Seta, Claws and Arolium)

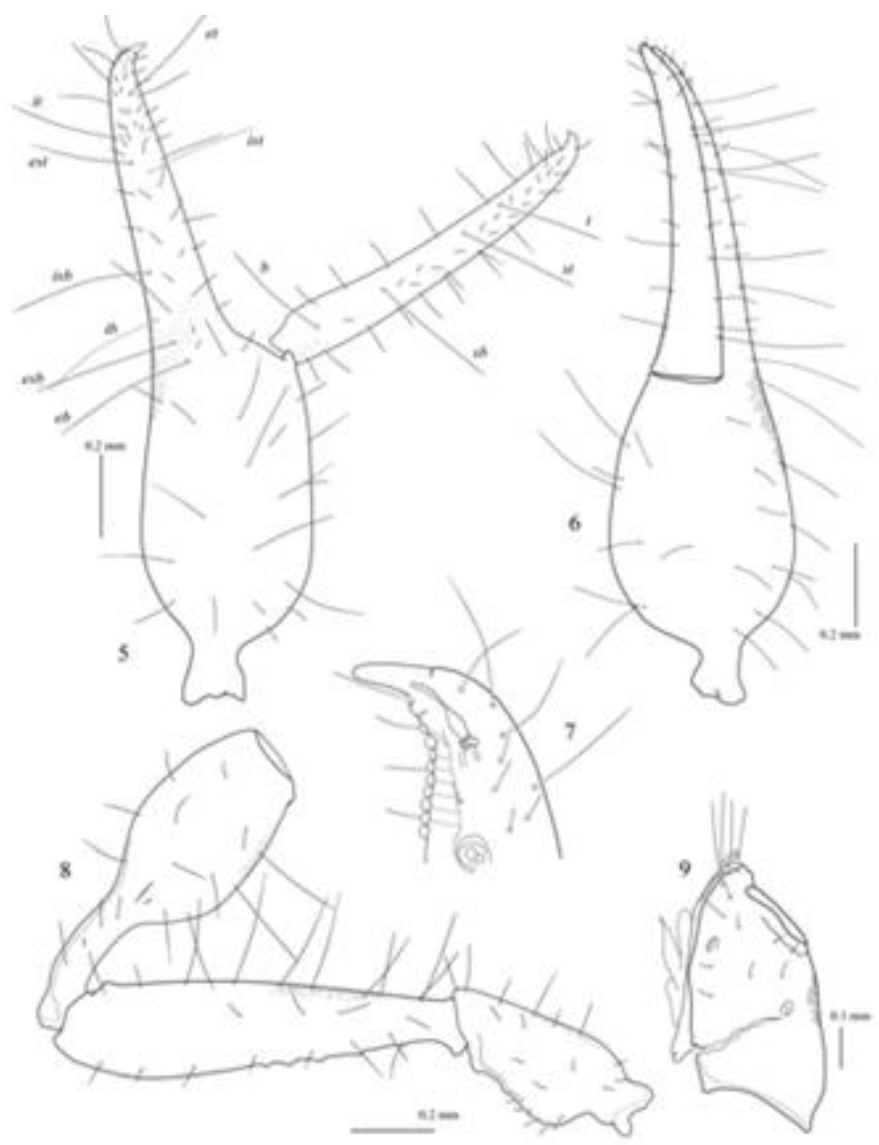

Figures5-9. Acanthocreagris Ronciformis (Redikorzev, 1949), Õ: 5. Right Chela, Lateral View (Showing the Trichobothrial Pattern); 6. Left Chela, Ventral View; 7. Tip of Fixed Chelal Finger (Showing the Position of Nodus Ramosus); 8. Basal Segments of Pedipalp, Dorsal View 9. Left Pedipalpal Coxa, Ventral View [Granulation Pattern is Not Shown Completely]

Microcreagris ronciformis Redikorzev, 1949: 643-644, figs 3, 4a.

\section{MATERial EXAMined}

IRAN: Khorasan Province: $1 \mathrm{O}^{\lambda}$, Bojnord [ $37^{\circ} 27^{\prime} \mathrm{N}, 57^{\circ} 18^{\prime} \mathrm{E}$, altitude $\left.1070 \mathrm{~m}\right]$, cranny into a house, leg. H. Sheikhnejad (IAUA).

\section{SHORT DESCRIPTION}

Male (Figs. 1-9)

Carapace: entirely smooth; 1.17 times longer than width; chaetotaxy: 4:6:6:6 (Fig. 1). Tergites: weakly sclerotized; entirely smooth; without median suture line; all segments with uniserate setae; X with two median long tactile setae; XI with four long tactile setae situated laterally and medially. Sternites: weakly sclerotized; entirely smooth; without median suture line; most setae shorter than the 
tergal setae; anterior operculum with grouped setae, posterior operculum with two pairs of anterior and a transverse row of posterior setae, VI-VIII with two central discal setae, and other segments with uniserate setae; X and XI with two median long tactile setae. Chelicera: galea with three terminal rami (Fig. 2); rallum with 8 blades (Fig. 3); serrula exterior with 19 and serrula interior with 12 blades; lamina exterior absent. Pedipalp: completely granulate except fingers (partly shown in illustrations); coxa with 12 setae, and two distinct lyrifissures, manducatory process with 3 long acute setae, one long acute seta situated very close to manducatory process (Fig. 9); trochanter L/W 2.30; femur L/W 4.63; patella with 3 lyrifissures (Fig. 8), L/W 2.83; chela (with pedicel) L/W 3.92; chela (without pedicel) L/W 3.55; hand (with pedicel) L/W 2.10; movable finger 1.05 times longer than hand (with pedicel); trichobothriotaxy as in Figs 5-6; fixed finger with 71 similar pointed teeth; movable finger with 61 teeth, 28 distal teeth large and rounded, 33 basal teeth small, oblong and blunt; nodus ramosus only present in fixed finger (Fig. 7). Legs: coxa I with an apical acute process; coxal setae arranged: chaetotaxy: right coxae 5:6:5:12, left coxae 7:7:5:14; sub-terminal setae branched (Fig. 4); arolia simple and shorter than claws; claws simple. Leg I: tibia L/D 3.60; metatarsus L/D 2.25; tarsus L/D 4.67. Leg IV: tibia L/D 6.50 (TS = 0.63); metatarsus L/D 2.20 (TS = $0.27)$; tarsus L/D $4.56(\mathrm{TS}=0.29)$.

Dimensions in mm: body length 2.52; carapace 0.82/0.70; Pedipalp: femur 1.02/0.22; patella (with pedicel) $0.85 / 0.30$; pedicel of patella 0.35 ; patella (without pedicel) 0.51 ; chela (with pedicel) 1.57/0.40; chela (without pedicel) 1.42; hand (with pedicel) 0.84 ; movable finger L. 0.88. Leg I: femur $0.37 / 0.11$; patella $0.30 / 0.11$; tibia $0.36 / 0.10$; metatarsus $0.18 / 0.08$; tarsus $0.28 / 0.06$. Leg IV: femur $0.33 / 0.20$; patella $0.40 / 0.19$; femur + patella 0.70 ; tibia $0.65 / 0.10$; metatarsus $0.22 / 0.10$; tarsus $0.41 / 0.09$.

\section{RESUlts AND DisCUSSION}

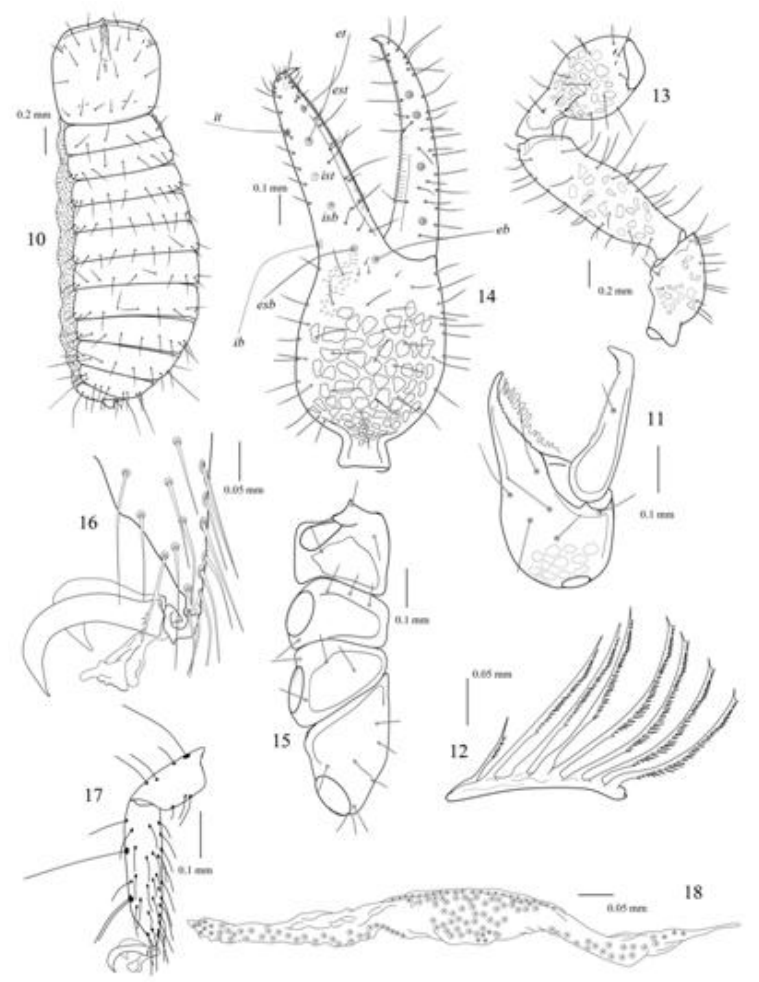

Figures10-18. Roncus Corimanus Beier, 1951, ㅇ: 10. Whole Body, Dorsal View (Showing the Chaetotaxy of Carapace and Tergites, Shape of Carapace and Type of Pleural Membrane); 11. Chelicera (Serrula Exterior Omitted); 12. Rallum; 13. Basal Segments of Pedipalp, Dorsal View; 14. Right Chela, Lateral View (Showing the Trichobothrial Pattern); 15. Right Coxae, Ventral View; 16. Tarsus IV (Showing Sub-Terminal Seta, Claws and Arolium); 17. Metatarsus and Tarsus IV (Showing Tactile Setae); 18. Cribriform Plate.

Acanthocreagris ronciformis (Redikorzev, 1949) was originally recorded from Turkmenistan by Redikorzev [10]. Subsequently, three species Acanthocreagris vachoni Mahnert, 1976 from Iran, A. aucta (Redikorzev, 1949) from Tajikistan and A. abaris Ćurčić, 1985 from Turkmenistan were synonymized with A. ronciformis [11]. Redikorzev [10] shows trichobothrium ist in the distal half of the fixed chelal finger in A. ronciformis, as is normal for the members of Acanthocreagris. It is 
therefore surprising that ist which is shown in a basal position in Curčić's figure [12] were correct. However, the more reasonable interpretation would be that the material which he described as $A$. aucta was misidentified and belongs to a different species. The observation of Ćurčić's [12] descriptions of the position of trichobothrium ist for these species which is discordant with the normal position for Acanthocreagris is interesting. Schawaller [13] didn't mention it when synonymizing them with $A$. ronciformis, but it is not sufficient to justify nomenclatural changes without checking the types of the species concerned and the male identified as A. aucta by Ćurčić [12]. Schawaller [13] probably assumed that Ćurčić's descriptions were incorrect. Therefore, the specimens of A. aucta, A. abaris and $A$. ronciformis must be reexamined to revalidation.

It is worthy to mention that A. ronciformis were collected from under stone in Shah PasandMazandaran Province [4] which is considered as a common habitat for the species. The newly collected material from Bojnord-Khorasan Province has been found in a wall crevice within a house which shows that it is capable to live inside houses.

Roncus corimanus Beier, 1951

Roncus (Roncus) corimanus Beier, 1951: 96-97, fig. 1.

\section{Material Examined}

IRAN: Mazandaran Province: 1 , , Amol [ $36^{\circ} 25^{\prime} \mathrm{N}, 52^{\circ} 21^{\prime} \mathrm{E}$, altitude $76 \mathrm{~m}$ ], litter and soil, Jun 2013, S. Paktinat (IAUA).

\section{REDESCRIPTION}

\section{Female (Figs 10-18)}

Carapace (Fig. 10): dark reddish brown; not granulate and entirely smooth; epistome distinctly present; slightly wider than length, widest at the middle, L/W with epistome 0.97 , L/W without epostome 0.94; with 2 small reduced eyes with flattened lenses (eyespots), situated very close to anterior margin; anterior margin with 4 and posterior margin with 6 setae; setae arranged: 4: 4: 4: 4: 6; all setae thin and simple; transvers furrows absent; with 6 very small lyrifissures.

Tergites (Fig. 10): brown, posteriors darker in color than anteriors, distinctly lighter in color than carapace; not granulate; lightly sclerotized; without median suture line; chaetotaxy: 6:10:11:11:11:11:11:11:2T5T2:1T7T1:T5T:2; setae long, acute and stouter than the setae on carapace.

Sternites: brown, slightly lighter in color than tergites; not granulate; poorly sclerotized; without median suture line; XI with one leaf-like process (sensillum) in each side; anterior operculum with minute setae which situated cluster like; posterior operculum with uniserate setae, arranged regularly based on the length of the setae; most setae longer than the setae on posterior operculum; cribriform plate elongate across the genital aperture (Fig. 18); anterior tracheal trunk distinctly larger than posterior; chaetotaxy: 9:(3)12(3):(2)10(2):13:13:13:12:11:2T2T2:1T2T1:2.

Pleural membrane (Fig. 10): roughly granulate.

Chelicera: brown, distinctly darker in color than anterior tergites; hand with 6 setae (Fig. 11); rallum with 8 denticulate blades, length of proximal blade about one third that of others (Fig. 12); galea absent or reduced as a bulge; galeal seta present and situated sub-distally; serrula exterior with 21 blades; serrula interior with 15 blades; fixed finger with 15 point and small teeth; movable finger with an apical lobe, 17 small teeth.

Pedipalps: dark reddish brown, darker in color than carapace; not granulate and entirely smooth; trochanter with one dorsal hump, L/W 2.13; femur with 2 long setae without enlarged alveoli situated medially, two slightly long setae present (Fig. 13), L/W 3.12; patella with 3 lyrifissures situated basally (Fig. 13), L/W 2.00; chela (with pedicel) L/W 2.82; chela (without pedicel) L/W 2.55; hand (with pedicel) L/W 1.46; movable finger 1.07 times longer than hand (with pedicel); fixed finger with 8 and movable finger with 4 trichobothria (Fig. 14); fixed finger with trichobothria et, it and est situated distally, trichobothrium ist situated in the middle of the finger, is $b$ situated on retrolateral face of the finger, between $i b$ and ist and trichobothria $i b, e b$ and $e s b$ situated basally; movable finger with trichobothrium $s b$ situated in the middle between $b$ and $s t$, trichobothrium $t$ and $s t$ situated in distal half of finger; fixed finger with 3 micro setae situated slightly proximal to $e b$ and 3 micro setae situated at the same level as $e s b$; hand with 4 long setae without alveoli situated basally; venom 
apparatus present in fixed finger, nodus ramosus situated distinctly distal to trichobothrium et; fixed finger with 55 teeth which reduced basally and movable finger with 50 uniform teeth.

Legs: brown, distinctly lighter in color than body; not granulate; coxa I with5, II with 6, III with 4 and IV with 8 simple, short and thin setae; coxa I with anterior tooth shape projection (Fig. 15); leg I: tibia L/D 4.00, metatarsus L/D 2.28 and tarsus L/D 4.83; leg IV: tibia L/D 4.71, metatarsus L/D 2.44 and tarsus L/D 4.11; tibia IV with one median tactile setae $(\mathrm{TS}=0.53)$; metatarsus with one tactile seta situated basally ( $\mathrm{TS}=0.20$ ) (Fig. 17 ); tarsus with one tactile setae situated basally (TS=0.36) (Fig. 17); sub-terminal setae branched (Fig. 16); claws simple; arolia undivided and shorter than claws.

Dimensions in mm: Body length $2.85 \mathrm{~mm}$; Carapace 0.80/0.80. Pedipalp: trochanter 0.47/0.22; femur $0.75 / 0.24$; patella $0.60 / 0.30$; chela (with pedicel) $1.27 / 0.45$; chela (without pedicel) 1.15 ; hand (with pedicel) L.0.66; movable finger L. 0.71. Leg I: tibia 0.36/0.09; metatarsus 0.16/0.07; tarsus 0.29/0.06. Leg IV: tibia 0.66/0.14; metatarsus 0.22/0.09; tarsus 0.37/0.09.

\section{RESUlt AND DiscusSiON}

Rancus $(R$.) corimanus was reported for the first time from Lahijan [1], and subsequently recorded from Chalous-Northern Iran [2]. Then, Roncus (R.) glaber Beier, 1962 collected from Georgia was synonymized with $R$. corimanus by Schawaller [5]. In the present time, the species is only known from Iran and Georgia [11].

The pedipalp of the recently collected specimen is slightly shorter and thinner than that of the type and also the female from Georgia, e.g. For example the pedipalpal femur size is $0.80-0.93 / 0.24-0.26$ $\mathrm{mm}$, the chelal hand (without pedicel) $0.70-0.84 / 0.48-0.58 \mathrm{~mm}$ and the movable chelal finger length is $0.70-0.75 \mathrm{~mm}$ for the materials which were previously studied $[1,2,14,15]$. Noticeably, the pedipalpal femur size of the newly collected specimen from Iran is $0.75 / 0.24 \mathrm{~mm}$, the chelal hand (with pedicel) is $0.66 / 0.45 \mathrm{~mm}$ and the movable chelal finger length is $0.71 \mathrm{~mm}$.

The most important difference between the newly collected female from Iran, the types and the female from Georgia is the pattern of granulation of the pedipalp. Beier [1] described the femur and the chelal hand of the type covered with granules, and also mentioned than the chelal hand of the female from Georgia is smooth $[14,15]$. Engagingly, the pedipalp of the newly collected specimen from Iran is entirely smooth except at the base of the fixed chelal finger (see Fig. 14). In addition, the presence of two long setae which are situated about in the median zone of the pedipalpal femur was not illustrated for the type and also for the specimen from Georgia (judging from Beier [1]: fig. 1a; Beier [14]: Fig. 193; Beier [15]: Fig. 2). These differences are not sufficient for recognizing a new species and can be probably regarded as the intraspecific variations within a group.

\section{Conclusion}

Synonymy means a genus/species has the same or almost the same characters as another genus/species which was previously described. A proposed synonymy of A. aucta, A. abaris and A. ronciformis is subjective (Schawaller [13]) and can be questioned and eventually corrected or uncorrected. In due attention to the position of thrichobothrium ist for these species, A. abaris and A. aucta may be removed from the synonymy of A. ronciformis, but it needs to check the types which are discussed here-in-before.

Intraspecific variation is changes within a species. Variation is frequent in the neobisiid species, so the use of this sort of differences to separate species is probably not valid, e.g. Redikorzev [10] described the types of $A$. ronciformis as having three rami, but the specimen which is examined here has four rami.

In respect to the Roncus species, the presence of a few inconsequential differences, e.g. chaetotaxy of the pedipalpal femur obtaining based on the only one male collected from Iran is not sufficient to recognize new species. So, more specimens must be considered to establish the changes presented here as intraspecific variation and should be directly compared with the type to erect a new species. In this study, the male is attributed to $R$. corimanus on the basis of the morphometric characters, the trichobothrial pattern and the geographical proximity.

\section{CONFLICT OF INTEREST STATEMENT}

The author declares that he has no competing interest and has not a financial relationship with the organization that sponsored the research. 


\section{ACKNOWLEDGMENT}

The author is grateful to the esteemed referees who reviewed the first draft of the manuscript which was submitted to Arachnology and provided the skillful comments those have made this research possible. Also, Mr. Saeed Paktinat and Mr. Hadi Sheikhnejad are here thanked for collecting these interesting specimens. The author is extremely thankful to Dr. Mark S. Harvey for his instruction, Dr. Reza Vafai Shoushtari for his support, an anonymous referee for his/her suggestions and Mr. Mahmoud Nassirkhani for his assistance.

\section{REFERENCES}

[1] Beier M., Ergebnisse der österreichischen Iran-Expedition 1949/50, Pseudoscorpione und Mantiden. Der Annalen des Naturhistorischen Museums in Wien, 58, 96-101 (1951).

[2] Beier M., Pseudoscorpione aus dem Iran, Der Annalen des Naturhistorischen Museums in Wien, 75, 357-366 (1971).

[3] Mahnert V., Roncus viti n. sp. (Arachnida, Pseudoscorpiones) aus dem Iran, Berichte des Naturwissenschaftlich-Medizinischen Vereins in Innsbruck, 61, 87-91 (1974).

[4] Mahnert V., Zur Kenntnis der Gattungen Acanthocreagris und Roncocreagris (Arachnida, Pseudoscorpiones, Neobisiidae), Revue Suisse de Zoologie, 83, 193-214 (1976).

[5] Schawaller W., Pseudoskorpione aus dem Norden des Iran (Arachnida: Pseudoscorpiones), Senckenbergiana biologica 63, 367-371 (1983).

[6] Chamberlin J.C.,The arachnid order Chelonethida,Stanford University Publications, Biological Sciences, 7(1), 1-284 (1931).

[7] Harvey M.S., The phylogeny and classification of the Pseudoscorpionida (Chelicerata: Arachnida), Invertebrate Taxonomy, 6, 1373-1435 (1992).

[8] Harvey M.S., Ratnaweera P.B., Randeniya P.V. and Wijesinghe M.R., A new species of the pseudoscorpion genus Megachernes (Pseudoscorpiones: Chernetidae) associated with a threatened Sri Lankan rainforest rodent, with a review of host associations of Megachernes,Journal of Natural History, 46, 2519-2535 (2012).

[9] Judson M.L.I., A new and endangered species of the pseudoscorpion genus Lagynochthonius from a cave in Vietnam, with notes on chelal morphology and the composition of the Tyrannochthoniini (Arachnida, Chelonethi, Chthoniidae), Zootaxa, 1627, 53-68 (2007).

[10] Redikorzev V., [Pseudoscorpionidea of Central Asia], Travaux de l'Institute de Zoologique de l'Académie Sciences de l'U.R.S.S. 8, 638-668 (1949).

[11] Harvey M.S., Pseudoscorpions of the World, version 3.00, Western Australian Museum, (2013). Available at: http://museum.wa.gov.au/catalogues-beta/pseudoscorpions [accessed 28 September 2015].

[12] Ćurćić B.P.M., A revision of some species of Microcreagris Balzan, 1892 (Neobisiidae, Pseudoscorpiones) from the USSR and adjacent regions, Bulletin of British Arachnological Society 6, 331-352 (1985).

[13] Schawaller W., Liste griechischer Neobisiidae mit neuen Höhlenfunden in Epirus, auf Samos und Kreta (Arachnida: Pseudoscorpiones), Stuttgarter Beiträge zur Naturkunde (A), 386, 1-8 (1985).

[14] Beier M., Ordnung Pseudoscorpionidea (Afterskorpione), In Bestimmungsbücher zur Bodenfauna Europas, vol. 1. Akademie-Verlag, Berlin (1963).

[15] Beier M., Über kaukasische Pseudoskorpione, Annalen des Naturhistorischen Museums in Wien, 64, 146-153 (1962). 